by Prof. R. W. Whytlaw-Gray and Dr. W. Cawood, the second on the method of limiting-densities, established by Prof. E. Moles. Prof. Jaquerod presided over the assembly, which was attended by Profs. Whytlaw-Gray (Leeds), Moles (Madrid), Lepape (Paris), Klemenc (Vienna), Timmermans (Brussels), Keesom (Leyden) and Dr. Cawood (Leeds). Several suggestions were made concerning the improvement of the methods used, and a discussion took place concerning the interpretation of the results obtained. Among the conclusions, the committee emphasized the international importance of the laboratories at Leeds (Whytlaw-Gray) and at Madrid (Moles), on account of the results they obtain, their equipment and the special qualifications of their staffs. This is to be reported to the International Organisation on Intellectual Co-operation of the League of Nations. The full reports and the minutes of the meeting will be published by the International Institute of Intellectual Co-operation. This meeting was a part of the projected scientific activity of the International Organisation on Intellectual Co-operation. Future assemblies of committees of study will be held this year and the following questions will be discussed : "New Vitamins"; "Nomenclature of Genetics"; "New Theories of Modern Physics" ; "Co-ordination of Scientific Terminologies" and "The Electric Double Layer".

\section{Scottish Universities Parliamentary Election}

ON January 20, a writ was issued for the Scottish Universities by-election, made necessary by the death of Mr. Ramsay MacDonald. A group of strong candidates is in the field : Sir John Anderson, former Governor of Bengal, the nominee of the Unionist Associations of the Universities; Prof. A. Dewar Gibb, regius professor of law in the University of Glasgow, a Scottish Nationalist; Dr. Frances H. Melville, formerly mistress of Queen Margaret College, University of Glasgow, an Independent candidate; and Sir Peter Chalmers Mitchell, biologist and former secretary of the Zoological Society of London, standing as an Independent Progressive. Sir Peter Chalmers Mitchell is a graduate of the University of Aberdeen as well as of the University of Oxford, and he has maintained contact, during a life devoted to biological science and administration, with the arts and with educational developments in Great Britain and abroad. He was secretary of the Zoological Society of London for thirty-two years, and for a long period was leader writer and scientific correspondent of The Times. At a meeting of Scottish graduates in London he stated that the principle of university seats in Parliament is most difficult to defend if these are simply to be held by official nominees of the political parties, and that he considers it the duty of university electors to select the candidate with the best qualifications to advocate the services which the arts and sciences can give the nation. Sir Peter is particularly well qualified to present and uphold in the House of Commons the scientific outlook upon modern problems touched by science, and on this account his election to Parliament would be widely welcomed.

\section{Centenary of James Craig Watson}

ON January 28 the centenary occurs of the birth of the American astronomer James Craig Watson, whose name is recalled by the Watson Medal of the National Academy of Sciences. He was born in Elgin County, Canada, of American-parents, and at the age of fifteen years he entered the University of Michigan at Ann Arbor, and there came under the influence of the German astronomer Franz Brünnow (1821-91) who in 1854 had been appointed the first director of the Ann Arbor Observatory. Watson soon became an enthusiastic astronomer and on Brünnow's resignation in 1863 he succeeded him as director of the Observatory and as professor of astronomy. He held these positions until 1879, when he was appointed director of the Washburn Observatory at the University of Wisconsin, Madison, where he died suddenly on November 22, 1880, at the early age of forty-two years. Watson became known by his discovery of the minor planet Eurynome, which he first observed in 1863. Afterwards he discovered twenty-one other similar bodies. In 1867 he published a valuable work on theoretical astronomy which became a standard text-book. He was one of those who journeyed to Sicily to observe the solar eclipse of December 22, 1870, and four years later he visited Peking to observe the transit of Venus, for which event the astronomical world had established some forescore posts of observation at a cost of about a quarter of a million. In 1870, by which year he had discovered seven minor planets, Watson was awarded the Lalande Medal of the Paris Academy of Sciences.

\section{Royal Astronomical Society's Awards}

THE gold medal of the Royal Astronomical Society has been awarded to Dr. William Hammond Wright, director of the Lick Observatory, Mount Hamilton, California, for his studies of the spectra of gaseous nebulæ and of novæ and for his work on the photography of planets in light of different colours. A bronze ('Jackson-Gwilt') medal and gift have been awarded to Mr. P. M. Ryves for his observations of variable stars and other astronomical work, and also to Mr. F. J. Hargreaves for his contributions to astronomy. The investigations of Dr. W. H. Wright on the spectra of the gaseous nebulæ comprise : (1) measurements of wave-lengths and of intensities of nebular lines; (2) the study of the nebular nuclei ; (3) the investigation of the distribution of nebular radiations throughout the nebulæ. Dr. Wright was the first to realize the importance in these observations of accurate guiding, without allowing the object to drift along the slit to lengthen the lines, in order to study the spectra of the nuclei and to derive information with regard to the localization of lines in some of nebulæ. He has recently returned to the study of the spectra of planetary nebulæ in the ultraviolet, taking advantage of the extension to shorter wave-lengths made possible by the coating of the 36-inch mirror of the Crossley reflector with aluminium. Mr. Ryves has for many years been a most assiduous and accurate observer of variable 
stars, and has communicated fifteen papers on that subject to the Society. Mr. Hargreaves has rendered important services to astronomy by the design of valuable instrumental accessories. He has devised an electric drive for telescopes which has been very successfully applied to the 28 -inch equatorial at Greenwich. He also constructed a "comparison image micrometer" with which he made double-star observations with an accuracy which compared very favourably with that of observations made with the filar micrometer. In addition, he has produced mirrors and other work of high excellence. His contributions to astronomical observation have been chiefly in the delineation of planetary detail, but he has given much attention to astronomical photography.

\section{Geological Society of London Awards}

THE council of the Geological Society has made the following awards: Wollaston Medal to Prof. Maurice Lugeon, of the University of Lausanne, in recognition of the value of his researches on the mineral structure of the earth, particularly in respect of the geological structure of the Alps and of mountain building ; Murchison Medal to Dr. Henry Howe Bemrose, in recognition of his researches upon the igneous rocks of the Lower Carboniferous of Derbyshire, and also upon the Pleistocene fauna of the same area ; Lyell Medal to Dr. John Pringle for his services to palæontological science, and particularly in recognition of his work in connexion with the Geological Survey and Museum; Wollaston Fund to Dr. Henry Francis Harwood, of the Imperial College of Science and Technology, in recognition of his research work on the chemistry of minerals and rocks ; Murchison Fund to Dr. Frank Coles Phillips, for his contributions to metamorphism and structural petrology; a moiety of the Lyell Fund to Dr. Sydney Ewart Hollingworth, for his work on the Lower Carboniferous rocks, and the structural geology of the Lake District and northern Pennines, and on the Vale of Eden glaciation; another moiety of the Lyell Fund to Dr. Frederick Murray Trotter, for his geological researches, especially on the glacial and post-glacial phenomena of the Eden Valley.

\section{$\varepsilon$ Aurigæ-a Super-giant Star}

UNTI the requisite details are available in the Astrophysical Journal regarding Dr. O. Struve's discovery of the precise nature of the eclipsing binary system of $\varepsilon$ Aurigæ, no useful comments can here be made. It may be inferred, however, from the Press reports that a study by Dr. Struve of the infrared spectrum of the star obtained with sufficiently high dispersion has shown that the chief component of the system is a super-giant star with a radius some 3,000 times that of the sun. The star of largest radius hitherto known is Antares, the radius of which is about 450 times the sun's. $\varepsilon$ Aurigæ, the light variation of which is of Algol type but with an exceptionally long period of $27 \cdot 1$ years, has long been the subject of intensive observation, mainly in Germany, in the United States and in Canada. The spectroscopic history of the star up to 1928 is summarized in "Handbuch der Astrophysik", 6, Pt. 2, 466 (1928). Results obtained at the Yerkes Observatory by Frost, Struve and Elvey at the last light minimum in 1928-29 are given in the publications of that observatory in vol. 7, Pt. 2. During the same epoch, Adams and Sanford were able to distinguish clearly on their high-dispersion spectra taken at Mount Wilson a faint component on the redward side of the enhanced lines and those of hydrogen. They pointed out the necessity of obtaining high-dispersion spectrograms of $\varepsilon$ Aurigæ at other epochs of the period of light variation in order to trace the origin of the faint spectral component.

\section{Recent Advances in Glass Technology}

TWENTY-ONE years ago was a strenuous period for British technologists, and in no field were the problems more urgent than in connexion with the production of glass for laboratory, optical and many other purposes ; thus the necessity of team-work brought the Society of Glass Technology into existence, and its coming-of-age has recently been celebrated. A series of lectures on "Glass in Modern Life", arranged by the Society in this connexion, recalled some of the veritable struggles of the period of the Great War, and the more ordered progress of this 'key industry' under the subsequent measure of protection accorded to it. Prof. W. E. S. Turner mentioned that the value of the production of the chemical and scientific glassware industries has risen from $£ 129,000$ in 1924 to $£ 250,000$ in 1937 , and is doubtless even higher today. Undoubtedly, the activities of the Society have contributed in no small degree to the possibility of this expansion, and the same is true of Prof. Turner himself and the Glass Technology Department at the University of Sheffield. The term 'glass' covers a very wide variety of chemical substances; when we find it being employed in these days (inter alia) for nuts and bolts, woven fabrics (of course for highly specialized purposes), and bricks for building, we may wonder whether the golden age of glass production is only just beginning. The list of lecturers also included Mr. Raymond McGrath and Mr. Bernard P. Dudding, who dealt with the applications of glass in their special fields of architecture and illuminating engineering respectively; and Dr. W. M. Hampton contributed a lecture on new developments in the field of optical glass. Although the production of optical glass may be a very minor activity from the business point of view, the experience gained in efforts to improve it has been invaluable in its. lessons for the larger-scale operations.

\section{Cave Paintings and Military Operations in Spain}

WHILE anxiety was felt generally throughout the world as to the fate which was likely to befall the artistic treasures of Spain until reassurance was given by Sir Frederic Kenyon's visit of inspection to the scene of hostilities, archæologists were no less perturbed at the thought of the damage which might be done to the priceless palæolithic paintings of the caves of northern and eastern Spain, both within the 